\title{
Analysis of the Situation of Chinese Middle School Students in Physical Education
}

\author{
Yu Shan ${ }^{1}$, Wang Xinna ${ }^{2}$, Guo Wei ${ }^{1}$ \\ 1) Xi`an University of Physical Education, Xi`an, Province Shaanxi, China \\ ${ }^{2)}$ He Bei Institute Of Physical Education, Province Hebei, China \\ shanyu.118@sina.com, 413203707@qq.com,61671757@qq.com
}

\begin{abstract}
The text investigates the situation of Chinese middle school students in the Physical Education. According to the survey results students in 12 middle schools in China, analysize the factors which affect the teaching status of the Physical Education, and put forward a series of reasonable recommendations.
\end{abstract}

Index Terms - Physical Education, Factors, situation.

\section{Introduction}

Currently, physical education occupies an important position in Chinese education. But the students still do not attach importance to physical education. Especially the girls do not like participating in sports $[1,2]$. The interesting of students in the physical education, directly impacts on the quality of physical education and the achievements of educational objectives [4]. The factors which affect the interesting of the Physical Education, including personal factors of students, teaching contents and teaching methods, space and facilities in the school, the impactions of social and family.

1.1. Research purposes. Physical education is an important part of education, how to improve the quality of physical education in the middle school, is the currently problem for Chinese PE teachers to resolve.

1.2. Research object. 2100 students who are in the age of 1218 years old in 16 middle schools in China.

1.3. Research manners. 2100 subjects have conducted a series of questionnaire surveys and interviews. According to the survey results, made a series of statistical tables to describe the problems in the physical education.

\section{Research results}

2.1. Got questionnaire results, calculated datum and obtained the following list. (Table 1-2, Pie chart 1, Graph 1).

Table 1. After-school schedule

\begin{tabular}{|c|c|c|c|c|c|c|}
\hline & Internet & Study & Sport & Shopping & Housework & Chat \\
\hline Boys & $29.3 \%$ & $59.6 \%$ & $50 \%$ & $17.3 \%$ & $26.7 \%$ & $33.3 \%$ \\
\hline Girls & $13.3 \%$ & $66.6 \%$ & $29 \%$ & $35 \%$ & $33 \%$ & $55.3 \%$ \\
\hline$\sum$ & $21.3 \%$ & $63.1 \%$ & $39.5 \%$ & $26.2 \%$ & $29.9 \%$ & $44.3 \%$ \\
\hline
\end{tabular}

This table is questionnaire survey of after-school schedule for Chinese 12-18 years old students in 16 middle schools. Students spend most of time to study after school. Because of academic education, students focus on studying, regard that physical education is dispensable. This point affect the effect and development of physical education .Compared with boys, the proportion of girls join in sports activities less than $21 \%$.

Table 2 The ratio of students to participate in sports

\begin{tabular}{|c|c|c|c|c|c|c|}
\hline & Games & $\begin{array}{c}\text { Gymnastic } \\
\text { s }\end{array}$ & Dance & $\begin{array}{c}\text { Athle- } \\
\text { tics }\end{array}$ & $\begin{array}{c}\text { Basketball } \\
\text { Football } \\
\text { Volleyball }\end{array}$ & $\begin{array}{c}\text { Tennis } \\
\text { Badminton }\end{array}$ \\
\hline Boys & $55.7 \%$ & $7 \%$ & $5.7 \%$ & $28.3 \%$ & $65 \%$ & $34.3 \%$ \\
\hline Girls & $63.3 \%$ & $25 \%$ & $17 \%$ & $19.3 \%$ & $20 \%$ & $18.7 \%$ \\
\hline$\Sigma$ & $59.5 \%$ & $16 \%$ & $11.4 \%$ & $23.8 \%$ & $42.5 \%$ & $26.5 \%$ \\
\hline
\end{tabular}

This table shows that girls like games more than other sports, but boys like playing Basketball, Football and Volleyball very much. Thus, mainly in the choice of girls to choose non-confrontational, no physical contact. Interesting and entertaining of games Attract girls.
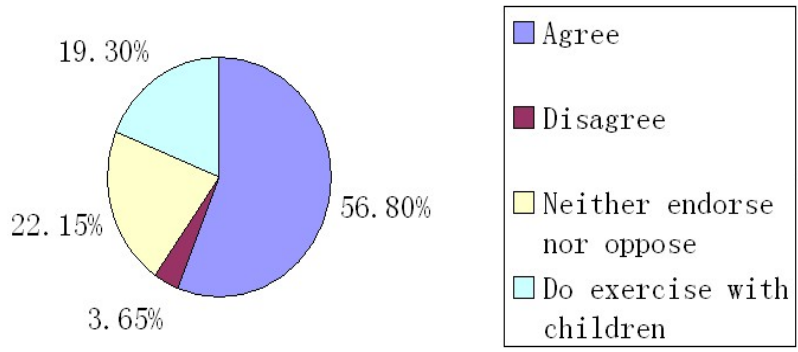

Pie chart 1. Parents' attitudes towards students join in sports.

The pie offers us the percentage of Chinese parents' attitude towards students join in sports. $56.80 \%$ parents agree their children join in sports; 3.65\% hold opposition attitude; $22.15 \%$ hold a neutral attitude; $19.30 \%$ parents do exercise with children. 


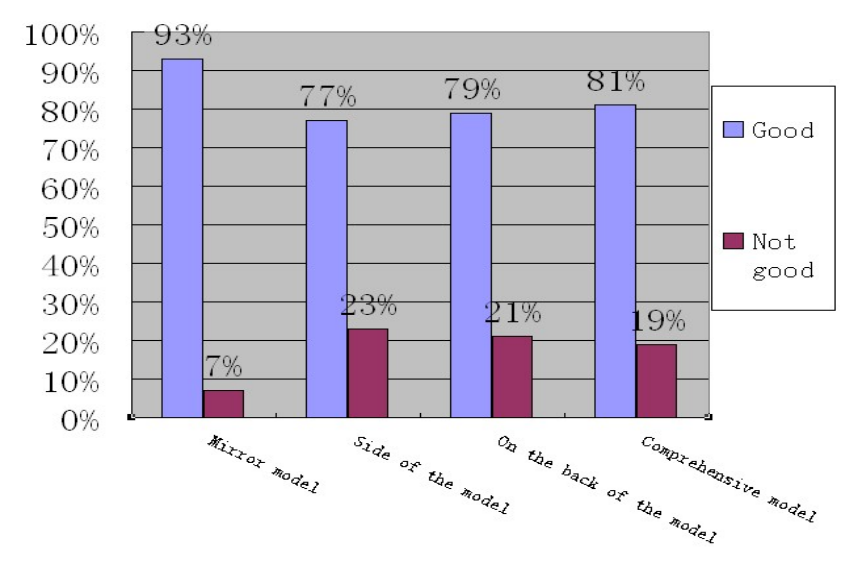

Graph 1. The investigation of model form.

Model enables practitioners to establish the right action representation, so that practitioners not only see each practice to make actions .Also need to see the connection of all the actions. This graph shows that $97 \%$ students consider mirror model is useful for studying sports technique;23\% students think that side of the model is very difficult for them to study sports technique.

2.2. Analyse the situation of girls in Chinese physical education.

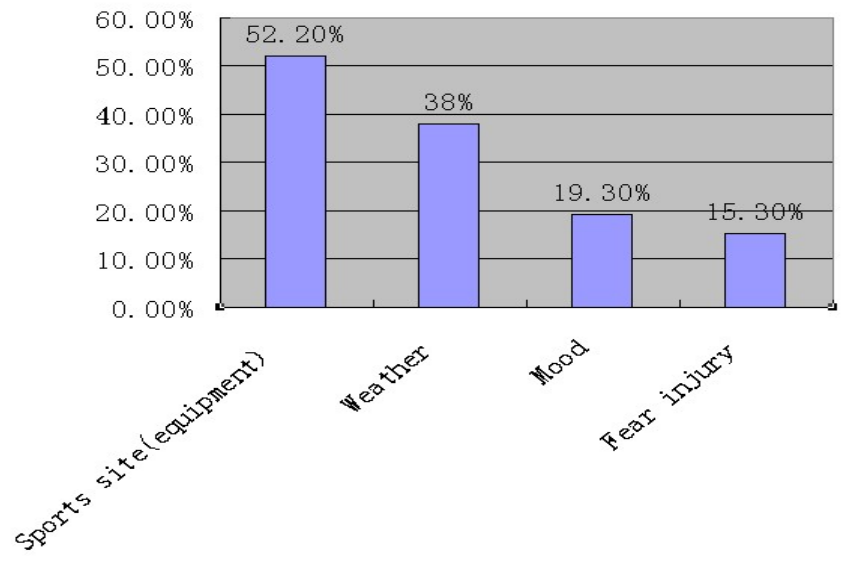

Graph 2. The factors of affect girls join in sports

The factors which affect the interesting of girls do sports, including personal factors, teaching contents and teaching methods, space and facilities in the school, the impactions of social and family. During Female puberty, physical and psychological characteristics have been changed a lot. Most girls like in a quiet, Lost the passion and enthusiasm to participation in physical exercise actively.

This graph shows that the most serious cause which affect girls join in sports is sports site (equipment). Sports facilities are the basis material conditions for students to join in sports. At the same time, it makes possible to achieve a variety of physical education. And plays an important role in increasing the interesting of students in the physical education. In recent years, many schools lack a comprehensive plan, regardless of the actual condition, expand the number of admissions, due to the lack of teaching equipment. If many classes have PE lessons at the same time , it will be reduced the choice of sports.

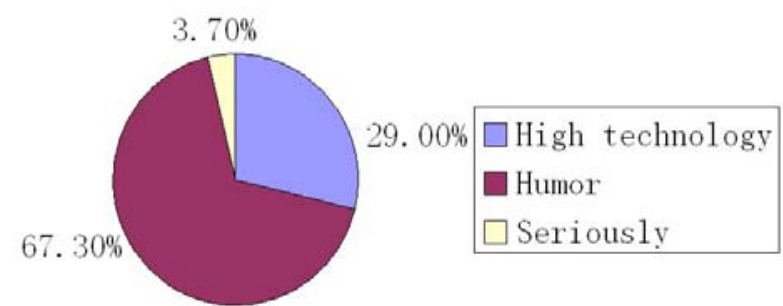

Pie chart 2. Investigate the type of physical education teacher

By investigating the type of physical education teacher, we know that most of students like humour teacher. Hummer make students have the opportunity to stress-free relaxed atmosphere, evaluate partners' actions, and express their views. It is useful for teacher to achieve teaching objectives. At the same time students also can develop the sense of competition and cooperation in capacity.

\section{Conclusions and Suggestions}

3.1 Make the students recognize the importance of physical education, increase in exercise physiology and sports medicine knowledge. So that students are able to understand sports have many benefits for health, in order to change passive learning to active learning.

3.2 Schools should increase investment in the hardware facilities, improve the construction of venues and facilities, increase students' per capita space for sports .Establish sports clubs in the school, for caring out to promote physical exercise and play Initiative and enthusiasm of students.

3.3 Continuously improve the quality of teachers, update teachers' professional knowledge and improve their professional standards .Teachers should improve teaching methods and make teaching contents become rich and interesting. Using encouraging language to enhance selfconfidence of students.

3.4 Families' attitude towards students join in sports also has a very wide range effects on physical education. Students in the family are whether encouraged to participate in sports regularly, parents can participate in sports with their children or not, have subtle influences for childrens' interesting in sports.

3.5 Make good sports protect ion and avoid sports injuries to overcome the fear of girls .Pay more attention to the suddenly physical discomfort on the girls.

3.6 The application of multimedia teaching software, such as watching videos, watching the game and other channels to enable students to comprehensive understand the sports. 


\section{References}

[1] Guo hailing. "The Research over Physical Education as well as the current situations of activities outside in PE from Teachers of Physical Education in Middle Schools": Hebei Normal University, 2012.

[2] Zhang Jianya, Zhang Kun, Shi Bing.”Study of present and strategy on physical education of middle schools in areas of northwest minorities in China”. Journal of Physical Education.: Vol.10 No.4, 2003, p.65-69.

[3] Xinbao Du. "Research on Physical Education Network of Middle School Education” ICETIS 2013: P556-558.
[4] Yan Ling. "Physical Education Teaching`s Effect on Middle School Students: Interpersonal Relations”, $17^{\text {th }}$ International Scientific Congress: Olympic Sport and Sport for All: 2013, P36.

[5] Guo Hua-ying. "Investigation analysis on the student`s physical training conditions in senior high schools", Journal of Sports Adult Education, 2004, Vol.20, No.3:P85-86.

[6] Tao Chunhua. "Interest and Countermeasures Physical factors affecting school girls”, Journal of Nanjing Institute of Physical Education, 2002, Vol.16, No.4: P55-56. 